\title{
Enhancement of electrokinetic remediation of lead and copper contaminated soil by combination of multiple modified electrolyte conditioning techniques
}

\author{
Oualid Mohamed Boulakradeche ${ }^{1 \dagger}$, Ouarda Merdoud ${ }^{1,2}$, Djamal Eddine Akretche ${ }^{1}$ \\ ${ }^{1}$ School Laboratory of Hydrometallurgy and Molecular Inorganic Chemistry, Faculty of Chemistry, University of Sciences and Technology Houari \\ Boumediene, Algeria \\ ${ }^{2}$ Centre of Research in Physical and Chemical Analysis (CRAPC), Algeria
}

\begin{abstract}
Electrokinetic soil remediation is often impeded by the aggregation of small particles, within soil, during the procedure. The soil porous network is subsequently clogged which results in immediate process termination. In order to overcome this limitation, the feasibility of electrokinetic remediation coupled simultaneously with two enhancing techniques was investigated: modified periodic polarity reversal and catholyte $\mathrm{pH}$ control The objective is to keep the soil pores unclogged in order to remove $\mathrm{Pb}$ and $\mathrm{Cu}$ from soil. Citric acid was used as anolyte, and 1 DCV.cm ${ }^{-1}$ was applied through the processing cell. This strategy showed 9.0 times better remediation results than that of unenhanced electroremediation. It was mainly owed to: (i) The $\mathrm{pH}$ adjustment that kept the catholyte ideally acid, thus avoiding the formation of metal hydroxide precipitates that could clog the soil pores. (ii) An increase of electro osmotic flow due to the modified polarity reversal technique. Approximately $96 \%$ of $\mathrm{Pb}$ and $\mathrm{Cu}$ were removed from soil. Duplicate results were obtained on soil with 10 -fold the initial heavy metals concentration. This combined configuration ensured an unclogged path within soil and enhanced electrokinetic mechanisms efficiency against pollutants remediation.
\end{abstract}

Keywords: Catholyte pH control, Copper, Electroremediation, Lead, Polarity reversal, Soil pores

\section{Introduction}

In the present time, environmental pollution is a worldwide crisis of varying intensity and significance. Soil bears the greatest burden of environmental pollution. It is getting contaminated in different ways, commonly of industrial origin and waste mismanagement [1]. One of the major chemicals involved in causing soil pollution are heavy metals. They are toxic, carcinogenic and strongly adsorbed onto the soil [2], which poses a risk to human, animal, and plant health. As a result, development of a clean-up strategy, which is based on a sustainable and economical solution, has widespread appeal.

Soil electrokinetic remediation (EKR) is one of the promising in situ soil cleaning techniques that is continuously being developed [3-6]. EKR process is suitable for low permeability soil where pollutants are trapped in grain pores, and thus difficult to remove. Recently, a considerable literature has grown up around the successful removal of heavy metals by soil EKR, such as: cadmium [7], arsenic [8], chromium [9], copper and lead [10]. However, the performance of this design is limited by some factors including: (i) the sorption and persistent behavior of heavy metals into the soil [3]. Their mobilization inside a porous media was found to be strongly dependent on the metal speciation [11]. That is why conventional EKR, which uses only deionized water as electrolytes, can only remove ionic form of metals that are available in the soil pores fluid [12]. (ii) Also, the $\mathrm{pH}$ gradient that is formed by water electrolysis in electrolyte chambers, and transported into the soil [13]: Hydrons $\left(\mathrm{H}^{+}\right)$favor the dissolution and extraction of heavy metals from the soil. Whereas, hydroxides $\left(\mathrm{OH}^{-}\right)$act as a bridging ligand to metals of concern, thus form hydroxides complexes that precipitate in soil [6]. (iii) Moreover, the effects of soil composition that may strengthen the retention of contaminants onto soil [14, 15]. These interferences clog the network of soil pores, and obstruct the proper functioning of EKR main mechanisms; electromigration and electroosmotic flow (EOF), that are
This is an Open Access article distributed under the terms of the Creative Commons Attribution Non-Commercial License (http://creativecommons.org/licenses/by-nc/3.0/) which permits unrestricted non-commercial use, distribution, and reproduction in any medium, provided the original work is properly cited.

Copyright (C) 2022 Korean Society of Environmental Engineers
Received April 03, 2021 Accepted June 26, 2021

${ }^{\dagger}$ Corresponding author

E-mail: mboulakradeche@usthb.dz

Tel: +21321247950 Fax: +21321247904

ORCID: 0000-0002-0814-3458 
responsible for the contaminants removal [3]. In order to optimize the soil EKR method, it is fundamental to exploit the advances that were made in this field to this day. In this context, researchers had explored different enhancing techniques [16-19]. One of which is acid enhanced EKR [20], using different organic, inorganic weak or strong acid [21, 22] as electrolytes; heavy metals are dissolved as a result of low pH environment created in soil. Citric acid is commonly used, at weak concentration, as anolyte to be transported into the soil by EOF. The benefits of this facilitating agent have been reported in many articles [12, 20]. Furthermore, one of main used EKR optimization is $\mathrm{pH}$ regulation. It is a key factor in preventing the formation of alkaline $\mathrm{pH}$ in soil which favors the sorption of heavy metals onto the soil [23]. Although, several practical solutions have been proposed to condition the soil $\mathrm{pH}$, catholyte $\mathrm{pH}$ control (Cpc) and polarity reversal are the most popular EKR enhancer. Cpc is coupled to EKR to prevent the high $\mathrm{pH}$ zone generated at the cathode chamber by adding diluted acid [24] directly into the catholyte. In the process, heavy metals are kept in soil under acid condition, and soil electrical conductivity is improved, thus facilitating the exit of pollutants outside the soil. In polarity reversal (or exchange polarity), the EKR polarity is switched for repetitive short intervals of time. The anode compartment is transformed into the cathode compartment, and vice versa. It is performed during enough time to allow water electrolysis to generate the necessary amount of $\mathrm{H}^{+}$in the anolyte (former catholyte), to neutralize the $\mathrm{OH}^{-}$ions. Thus, preventing the complexation of metals in soil and favoring their dissolution [25].

To summarize, the path of remediation needs to remain clear or without impeding obstruction that may clog the soil, and therefore limit the EKR process. The main objective of this work is to ensure a decontamination path within the soil pores, during the EKR time, for maximum heavy metals removal. The study was achieved through the combination of three EKR enhancing techniques: (i) Catholyte $\mathrm{pH}$ control with acetic acid; (ii) Periodic polarity reversal technique. Also, (iii) the feasibility of increasing the electric voltage, during a reduced polarity reversal time, was explored. The effectiveness of this boosting EKR approach was demonstrated through the application of each enhancing techniques individually and simultaneously together on soil electroremediation. The experiments were conducted under constant voltage gradient of 1 DCV. $\mathrm{cm}^{-1}$ on $\mathrm{Cu}$ and $\mathrm{Pb}$ spiked sand. Citric acid and sodium nitrate were used as purging solution in the EKR treatment. The performances of this work was evaluated through the aspect of $\mathrm{Pb}$ and $\mathrm{Cu}$ removal efficiency, heavy metals concentration, electroosmotic flow, influence of soil $\mathrm{pH}$, soil moisture and energy consumption of the process.

\section{Materials and Methods}

\subsection{Choice of Soil and Metal Concentration}

Sahara Desert constitutes 84\% of Algeria's land surface area. The underground of this barren area comprises a massive water underground reserve (it is estimated to 6.8 billion $\mathrm{m}^{3}$ ) [26]. In this country the majority of military shooting ranges are situated in the desert. $\mathrm{Pb}$ and $\mathrm{Cu}$ molecules in shooting range are most likely to be transported by rainwater to the underground and contaminate this precious water reserve. In this study a sandy soil was chosen to simulate the contamination of $\mathrm{Pb}$ and $\mathrm{Cu}$ from a shooting range. The soil used in this work was collected from the dunes of Adrar's desert situated in Algeria. The choice of contaminants concentration in this research was based on the amount of copper and lead usually present in shooting range. [27].

\subsection{Soil Preparation}

The soil was previously characterized by Boulakradeche and Cameselle [28], the main results are showed in Table 1. The sample was sieved through a $<2 \mathrm{~mm}$ stainless steel mech. It was subsequently spiked with copper nitrate and lead nitrate in order

Table 1. Physicochemical Properties of Soil Used in the Experiments

\begin{tabular}{|c|c|c|}
\hline Properties & Value & Method \\
\hline \multicolumn{3}{|l|}{ Soil particle distribution $\%$} \\
\hline$>50$ and $<2,000 \mu \mathrm{m}$ & 96 & \\
\hline$>20$ and $<50 \mu \mathrm{m}$ & $<3$ & Sieving \\
\hline$<20 \mu \mathrm{m}$ & $<1$ & \\
\hline Soil moisture \% & 4 & Thermogravimetric \\
\hline $\mathrm{pH}$ & 5.2 & USEPA SW-846 Method 9045D \\
\hline Electrical conductivity (mS/cm) & 0.34 & ISO 11265 \\
\hline Point of zero charge pH (PZCpH) & 3.1 & PZCpH with Long equilibrium time method \\
\hline Total organic carbon \% (TOC) & 1.3 & ISO 10694 \\
\hline \multicolumn{3}{|l|}{ The major minerals (weight \%) } \\
\hline $\mathrm{Si}$ & 22.96 & \multirow{4}{*}{ Characterized by SEM/EDX } \\
\hline B & 10.92 & \\
\hline $\mathrm{Al}$ & 1.72 & \\
\hline $\mathrm{Mg}$ & 1.50 & \\
\hline \multicolumn{3}{|l|}{ Heavy metals (mg. $\mathrm{kg}^{-1}$ ) } \\
\hline $\mathrm{Cu}$ & 3 & \multirow{2}{*}{ EPA Method 3050} \\
\hline $\mathrm{Pb}$ & $<1$ & \\
\hline
\end{tabular}


to obtain approximately $1,000 \mathrm{mg} \cdot \mathrm{kg}^{-1}$ of each metal. Another simulation sample was prepared with the same pollutants at 10,000 $\mathrm{mg} \cdot \mathrm{kg}^{-1}$ concentration of each metal. The samples were homogenized, air dried and aged under a fume hood in room temperature for 8 months. The purpose of this step was to strengthen the metals sorption into the soil, thus simulating a real contaminated soil. The equilibrium concentration of $\mathrm{Cu}$ and $\mathrm{Pb}$, after the aging period, were respectively: $933 \pm 26.21$ and $920 \pm 27.14 \mathrm{mg} . \mathrm{kg}^{-1}$ for the first soil sample; $9,720 \pm 245.91$ and 9,821 $\pm 228.82 \mathrm{mg} \cdot \mathrm{kg}^{-1}$ for the second soil sample.

\subsection{Experimental Set Up}

The electrokinetic cell used in this work comprises three glass compartments: the main compartment and two electrode compartments. The soil is introduced in the central compartment, which is a cylindrical tube of $140 \mathrm{~mm}$ length and a capacity volume of $453 \mathrm{~cm}^{3}$. The electrode compartments have a working volume of $300 \mathrm{~cm}^{3}$. They contain the electrolyte solutions and the carbon graphite electrodes. The effective surface contact of the latter is $40 \mathrm{~cm}^{2}$. Gas vent valves, located at the top of both electrode chambers, allow a controlled release of the gas generated by electrolysis of water. The flushing solutions are continuously homogenized with a magnetic stirrer. The three compartments are hold together by two socket threaded cups, as shown in Fig. 1. The contaminated soil is separated from the electrolytes by a fritted glass membrane and a glass microfiber filters (Whatman GF/C). A power supply is directly connected to the electrodes. The cumulative

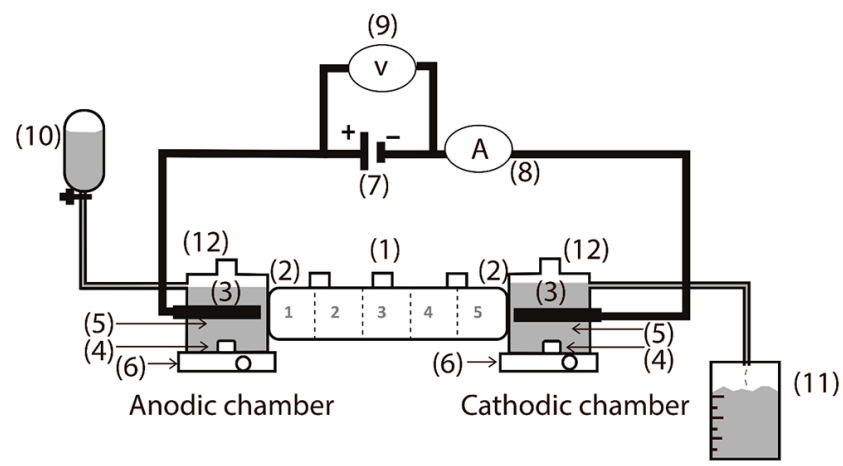

Fig. 1. Experimental setup: (1) Soil specimen, (2) Glass microfiber filter and porous stone, (3) Electrode, (4) Magnet, (5) Electrolyte, (6) Magnetic stirrer, (7) DC power supply, (8) Ampere meter, (9) Voltmeter, (10) Feeding bottle, (11) Expansion vessel, (12) Gas vent valve. electroosmotic flow is collected in a glass beaker placed near the cathode. On the other cell's end, an anolyte feeding reservoir (1 L) is attached in order to compensate the liquid drained by the electroosmotic flow. The two electrode chambers were levelled evenly in order to eliminate hydraulic gradient across the specimen.

\subsection{Electrokinetic Procedures}

In this work, EKR was performed on two level of soil contamination:

- Soil 1: The soil was mixed with $1,000 \mathrm{mg} / \mathrm{kg}$ of $\mathrm{Pb}$ and 1,000 $\mathrm{mg} / \mathrm{kg}$ of $\mathrm{Cu}$.

- Soil 2: The soil was contaminated with $10,000 \mathrm{mg} / \mathrm{kg}$ of $\mathrm{Pb}$ and $10,000 \mathrm{mg} / \mathrm{kg}$ of $\mathrm{Cu}$.

Each experiment was performed with $280 \mathrm{~g}$ of dry contaminated soil. The sample was thoroughly mixed with $110 \mathrm{~mL}$ of deionized (DI) water in all experiments. The soil moisture aimed in each mixture (liquid, soil) was 40\%. The sample was carefully placed and compacted in the central compartment. Then, $300 \mathrm{~mL}$ of appropriate electrolytes were poured in each electrode compartments. Table 2 summarizes the experimental conditions of each test. All experiments were performed under a constant DC voltage gradient of $14 \mathrm{~V}\left(1 \mathrm{~V} \cdot \mathrm{cm}^{-1}\right)$ during 19 to $29 \mathrm{~d}$. The daily measures were the cumulated EOF, current intensity, electrolytes $\mathrm{pH}$ and specific electrical conductivity.

\subsection{Polarity reversal and Catholyte $\mathrm{pH}$ Control}

Polarity reversal (PR) was applied during three hours by alternating the polarity of the electric generator and keeping the same voltage (14 DCV). The daily application frequency was three times a day $\left(3.0 \mathrm{~d}^{-1}\right)$ spaced out by two hours of normal elektrokinetic treatment (without PR), as depicted in Fig. S1(a). Catholyte pH control (Cpc) was carried out by connecting the cathode chamber to a $\mathrm{pH}$ controller, and injecting acetic acid of $1 \mathrm{M}$ solution to adjust the catholyte $\mathrm{pH}$ to a specific value of $\mathrm{pH}=4$.

The simultaneous use of PR and Cpc was carried out at the same rate of application as mentioned above. When PR and Cpc were combined with higher voltage, the polarity reversal application frequency was kept the same $\left(3.0 \mathrm{~d}^{-1}\right)$ but the duration time was reduced to $30 \mathrm{~min}$, and the electric voltage was risen up to $42 \mathrm{~V}$, only during the PR half hour application. Afterward, the voltage was set back to its original value (14 V), as depicted in Fig. S1(b).

\subsection{Analytical Methods}

\subsubsection{Soil characterization}

The chemicals used in this study are of analytical grade, all solutions

Table 2. Experimental Configuration of All EKR Tests

\begin{tabular}{|c|c|c|c|c|c|}
\hline Test & Anolyte & Main compartment & Catholyte & Controlled parameters & Time (d) \\
\hline $\mathrm{T} 1$ & $\mathrm{NaNO}_{3}(0.1 \mathrm{M})$ & Soil 1 & $\mathrm{NaNO}_{3}(0.1 \mathrm{M})$ & -- & 19 \\
\hline $\mathrm{T} 2$ & Citric acid $(0.1 \mathrm{M})$ & Soil 1 & $\mathrm{NaNO}_{3}(0.1 \mathrm{M})$ & -- & 19 \\
\hline $\mathrm{T} 3$ & Citric acid $(0.1 \mathrm{M})$ & Soil 1 & $\mathrm{NaNO}_{3}(0.1 \mathrm{M})$ & PR & 19 \\
\hline $\mathrm{T} 4$ & Citric acid $(0.1 \mathrm{M})$ & Soil 1 & $\mathrm{NaNO}_{3}(0.1 \mathrm{M})$ & Сpc & 19 \\
\hline $\mathrm{T} 5$ & Citric acid $(0.1 \mathrm{M})$ & Soil 1 & $\mathrm{NaNO}_{3}(0.1 \mathrm{M})$ & $\mathrm{PR}+\mathrm{Cpc}$ & 19 \\
\hline T6 & Citric acid $(0.1 \mathrm{M})$ & Soil 1 & $\mathrm{NaNO}_{3}(0.1 \mathrm{M})$ & High voltage $\mathrm{PR}+\mathrm{Cpc}$ & 19 \\
\hline D7 & Citric acid $(0.1 \mathrm{M})$ & Soil 2 & $\mathrm{NaNO}_{3}(0.1 \mathrm{M})$ & High voltage $\mathrm{PR}+\mathrm{Cpc}$ & 29 \\
\hline
\end{tabular}


were prepared using DI water. The soil was analyzed with scanning electron microscopy (SEM) from FEI model Quanta 400, coupled to a microanalyzer X type from EDAX, model Ametex [28]. The soil $\mathrm{pH}$ and electrical conductivity were determined by Thermo scientific orion 5 star plus meter respectively, with a ratio of 1:2.5 soil to water [29]. Total organic carbon was analyzed with Multi N/C 3100 from Analytik Jena AG (Germany) by dry combustion technique [30]. $\mathrm{Pb}$ and $\mathrm{Cu}$ content in soil sample were determined by acid digestion followed by flame atomic absorption spectroscopy analysis (Thermo Scientific, model ICE 3500) [31].

\subsubsection{Electrokinetic assessment}

Upon completion of each procedure, the electrode chambers were emptied. The electrolytes along with EOF liquid were stored in individual glass bottle at $4^{\circ} \mathrm{C}$ for metal analysis. Soil specimen was carefully extruded from the central tube of the electrokinetic cell and was sliced in five equal pieces numbered between 1 and 5 from anode to cathode, as shown in Fig. 1. Five grams of soil was sampled, from each soil slice, to determine the soil moisture content (in dry basis) [32]. Subsequently, the rest of the treated segments were dried and mixed separately into powder form in order to make the $\mathrm{Cu}$ and $\mathrm{Pb}$ concentration homogeneous within each sample. Finally, the electrolyte solutions along with the five soil samples were analyzed for $\mathrm{pH}$, electric conductivity (EC) and $\mathrm{Pb}, \mathrm{Cu}$ content.

All $\mathrm{Cu}$ and $\mathrm{Pb}$ chemical extraction and analysis procedures were performed in accordance with EPA Method 3010 and Method 3050 $[31,33]$. The metals concentration was determined by Flame atomic absorption spectroscopy and analyzed in triplicate. The results were within the Standard deviation range of $\pm 4 \%$. In each experiment, a mass balance analysis was calculated. Removal efficiency of each test was obtained by Eq. (1) as follow:

$$
R \%=\frac{(C i-C f)}{C i} \times 100
$$

Where $\mathrm{Ci}$ is the initial metal $(\mathrm{Pb}$ or $\mathrm{Cu})$ concentration in soil and $C f$ is the metal $(\mathrm{Pb}$ or $\mathrm{Cu})$ concentration remained in soil after EKR treatment.

In this study, power consumption $(P C)$ is expressed as the electric energy $(\mathrm{kWh})$ required to process 1 ton of contaminated dry soil (Eq. (2)).

$$
P c=\frac{1}{\mathrm{~m}} \int_{0}^{t} I \varphi \cdot d t
$$

Where: $\varphi$ (Volt) is the electrical DC voltage, a constant in these experiments, $I$ (A) is the current intensity of the EKR cell at time $t(\mathrm{~s})$, and $\mathrm{m}$ (ton) is the processed mass of dry contaminated soil.

\section{Results and Discussion}

The results obtained in the physicochemical characterization of soil, as shown in Fig. S2 and detailed in Table 1, indicates that the soil is fine sand, basically composed of silicon and boron as major elements along with aluminum and magnesium as minor elements.

\subsection{Current intensity and Soil Moisture}

The current intensity ( $I$ ) versus elapsed EKR time is represented in Fig. 2(a). The (I) of test T1 and T2 could not be sustained at the high starting level for more than $4 \mathrm{~d}$. It was mainly due to a high depletion of ionic species in the medium. Fig. 2(c) and 2(d) shows the initial and final soil moisture (SM) of the 7 tests carried out in this study. The soil sections 2, 3 and 4 of tests $\mathrm{T} 1$ and $\mathrm{T} 2$ showed poor (SM) values, ranging from 28.5 to $21 \%$, as they were all below the initial (SM). Therefore, indicating a considerable dewatering of soil pores. Since ions and pore water are the sine qua non of electric current in soil, the (I) was expected to stope in the prevailing conditions. The cause of soil dewatering could be due to the clogging of soil pores by precipitates of complexed metals in basic soil $\mathrm{pH}$.

In the tests, T3 and T4 (I) started initially at approximatively $40 \mathrm{~mA}$, then decreased and fluctuated until the $12^{\text {th }}$ day of EKR treatment, and subsequently stabilized below $10 \mathrm{~mA}$. The soil moisture of these tests was enhanced above the initial (SM). In PR technique, the reversal of polarity in EKR cell will reverse the cathode and anode (as explained in the introduction), $\mathrm{H}+$ ions are now being generated into the new anode (former cathode) which will re-dissolve $\mathrm{Pb}$ and $\mathrm{Cu}$ precipitates in soil. Consequently, the movement of pore fluid was enhanced by unclogging the soil pores from metal precipitates, and enriched the medium with ions, therefore an appropriate level of (SM) was maintained and the current intensity was enhanced [34]. Cpc favored the movement of $\mathrm{H}^{+}$, supplemented $\mathrm{CH}_{3} \mathrm{COO}^{-}$onto the soil and increased the EOF which enhanced the (SM). The application of both techniques in test T5, T6 and D7 resulted in the best (I), as shown in Fig. 2(b), values which were sustained at a high level. This phenomenon could be attributed to a better flow of water in the soil, and suggests the absence of soil pore clogging phenomenon by any precipitating molecules or small soil particles.

\subsection{Soil $\mathrm{pH}$}

In this work, soil electrokinetic remediation was highly dependent on soil $\mathrm{pH}$. Especially with citric acid which efficiency was strongly related to its predominant forms, $\mathrm{CitH}_{3}, \mathrm{CitH}_{2}^{-}, \mathrm{CitH}^{2-}$ and $\mathrm{Cit}^{3-}$ with respective acid dissociation constant (pKa) values of 3.10 , 4.80 and 6.39 [35]. However, electrokinetic soil remediation has a tendency to form basic front in the cathode and acid front in the anode due to the electrolysis of water.

In Tests $\mathrm{T} 1$ and $\mathrm{T} 2, \mathrm{H}^{+}$were produced by oxidation of water at the anode, and $\mathrm{OH}^{-}$were formed by reduction of water at the anode [9]. These ions electromigrated toward the soil and caused $\mathrm{pH}$ changes in different parts of the soil: acid in sections 1, 2 and basic in sections 3, 4, 5, as shown in Fig. 3(a).

The negative effect of electrolysis in the following experiments (T3-D7), as presented in Fig. 3(a), and 3(b) was reduced because the $\mathrm{OH}^{-}$generated at the cathode were neutralized by the $\mathrm{pH}$ control 

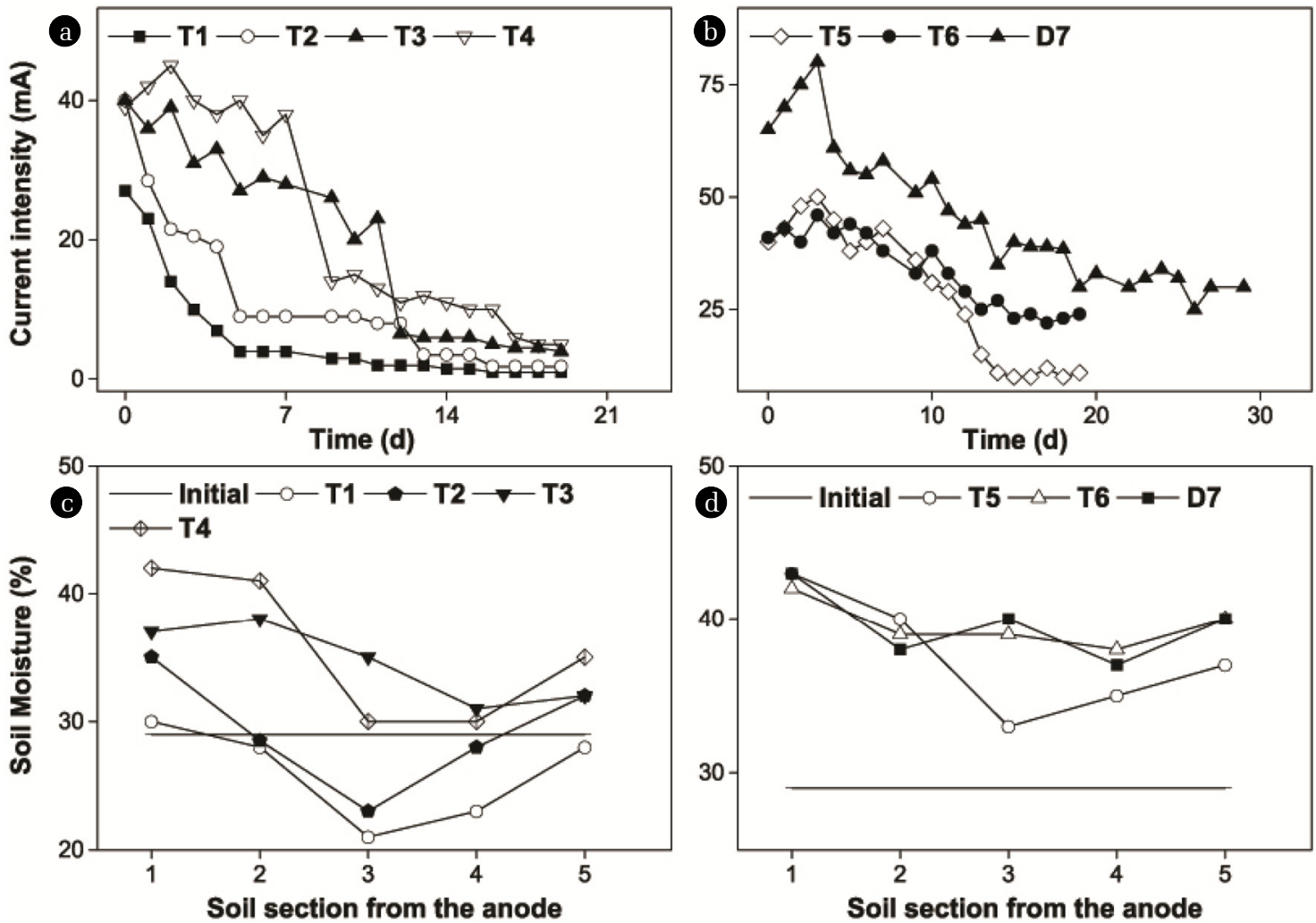

Fig. 2. Current intensity profile (a), (b) in electrokinetic tests, and soil moisture variation (d), (c) of before - after treatment in all experiments.
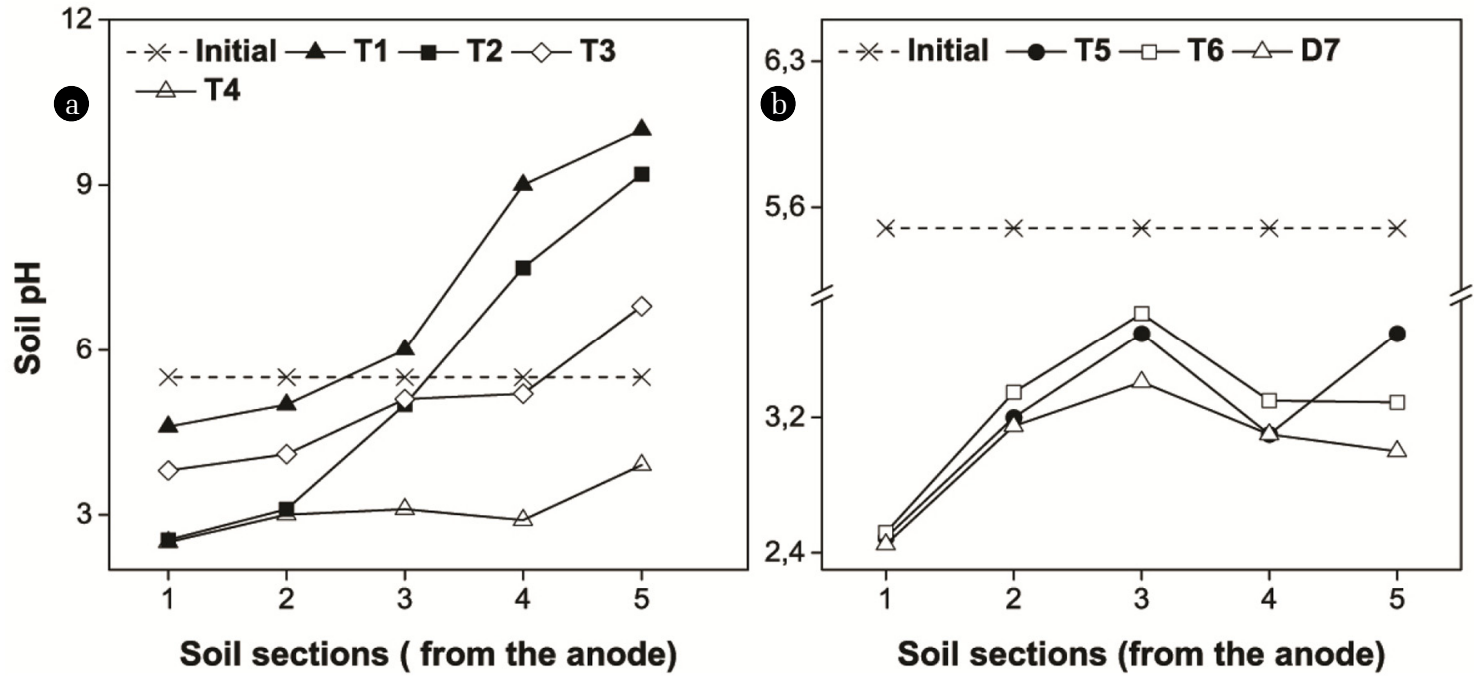

Fig. 3. Soil $\mathrm{pH}$ at the end of electrokinetic tests.

techniques. In test $\mathrm{T} 3$, the $\mathrm{pH}$ was 3.8 in section 1 and 6.8 in section 5, owing to the polarity reversal technique. During PR time the poles of water electrolysis were inverted which retarded the formation of basic medium near the cathode. In test T4 to D7 the soil remained acid with $\mathrm{pH}$ values below 3.9. Acetic acid was directly injected, in these experiments, into the catholyte in order to counter the alkaline environment yielded in the cathode. The amount of $\mathrm{H}^{+}$consumed to control the catholyte $\mathrm{pH}$ can be estimated as follow: 1 mole of $\mathrm{e}^{-}$produces 1 mole of $\mathrm{OH}^{-}$, and therefore needs 1 mole of $\mathrm{H}^{+}$to neutralize it [23]. The consumed amount of $\mathrm{H}^{+}$increased from test $\mathrm{T} 4$ to D7, respectively 1.38 and $3.04 \mathrm{~mol} . \mathrm{kg}^{-1}$, as presented in Table 3 . This was owed to the difference of current intensity which produced higher amount of $\mathrm{OH}^{-}$. 
Table 3. The Main Soil Electrokinetic Remediation Results of All Tests

\begin{tabular}{|c|c|c|c|c|c|c|c|}
\hline Test & Controlled parameter & $\mathrm{R} \%(\mathrm{Cu})$ & $\mathrm{R} \%(\mathrm{~Pb})$ & $\begin{array}{c}\text { Average S.M } \\
\text { (\%) }\end{array}$ & EOF (mL) & $\begin{array}{c}\text { consumed H+ } \\
(\text { mol.kg-1) }\end{array}$ & 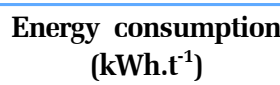 \\
\hline $\mathrm{T} 1^{\mathrm{a}}$ & -- & 11.18 & 11.65 & 26.00 & 44.00 & -- & 121.80 \\
\hline $\mathrm{T}^{\mathrm{a}}$ & -- & 32.85 & 30.53 & 32.00 & 138.00 & -- & 235.56 \\
\hline $\mathrm{T}^{\mathrm{a}}$ & PR & 62.19 & 58.82 & 35.00 & 126.50 & -- & 455.40 \\
\hline $\mathrm{T} 4^{\mathrm{a}}$ & Сpc & 74.56 & 65.47 & 36.00 & 230.50 & 1.38 & 519.60 \\
\hline $\mathrm{T} 5^{\mathrm{a}}$ & $\mathrm{PR}+\mathrm{Cpc}$ & 92.73 & 87.32 & 38.00 & 251.00 & 1.79 & 672.00 \\
\hline $\mathrm{T} 6^{\mathrm{a}}$ & Modified PR + Cpc & 99.11 & 97.13 & 41.00 & 492.00 & 2.04 & 768.00 \\
\hline $\mathrm{D} 7^{\mathrm{b}}$ & Modified PR + Cpc & 97.22 & 92.67 & 45.00 & 732.00 & 3.04 & $1,556.00$ \\
\hline
\end{tabular}

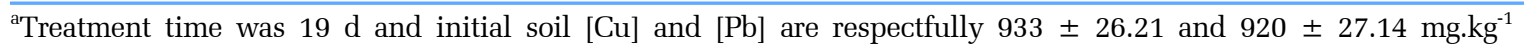

${ }^{\mathrm{b}}$ Treatment time was $29 \mathrm{~d}$ and initial soil $[\mathrm{Cu}]$ and $[\mathrm{Pb}]$ are respectfully 9,720 \pm 245.91 and 9,821 $\pm 228.82 \mathrm{mg} . \mathrm{kg}^{-1}$

\subsection{Electroosmotic Flow}

The direction of the EOF in all experiments was potentially from the anode to the cathode compartment during the EKR process. The electroosmotic flow was relatively low when compared with other experiment in the literature [8, 36]. According to HelmholtzSmoluchowski theory, electroosmotic flow is strongly related to the soil zeta potential $(\zeta)$, the dielectric constant of the fluid (D), the fluid viscosity $(\eta)$, and the electric potential $\left(E_{z}\right)$, as shown in Eq. (3): [6, 37]:

$$
q_{e o}=n A E_{z} \frac{D \zeta}{\eta}
$$

Where $\mathrm{q}_{\mathrm{eo}}$ is the volumetric flow rate, $\mathrm{A}$ is the cross sectional area of the soil and $\mathrm{n}$ is the porosity. There is no significant difference regarding the porosity of soil, the voltage gradient applied through the same EKR cell, or the viscosity of each diluted fluid used in this study. The conditions were approximatively the same apart from the important ionic strength of test D7 due to the quantity of heavy metals present in soil. Consequently, EOF was influenced by soil zeta potential variation, where negative $\zeta$ favors the electro- osmotic flow in the direction of the cathode, and positive $\zeta$ stops and could reverse the direction of EOF. Zeta potential is dependent on the interactions between the pore fluid and the soil particles, these interactions are strongly affected by pore fluid $\mathrm{pH}$ and ionic strength of the soil [38, 39]. Thus, the EOF difference between all experiments, as presented in Table 3, can be attributed to the variation of interstitial fluid $\mathrm{pH}$. Typically, soil zeta potential is neutral at the point of charge zero $\mathrm{pH}\left(\mathrm{PZC}_{\mathrm{pH}}\right)$, and acquires positive value when soil $\mathrm{pH}$ is reduced beyond $\mathrm{PZC}_{\mathrm{pH}}$, and negative value when soil $\mathrm{pH}$ is higher than $\mathrm{PZC}_{\mathrm{pH}}$ [40].

As presented in Fig. 4(a), cumulative EOF of tests T1 and T2 were relatively low due to the precipitation of metals in basic soil $\mathrm{pH}$ near the cathode which in turn clogged the soil pores. In Tests $\mathrm{T} 3$, T5 and $\mathrm{T} 6$ the soil was in acid environment which lead to a final average soil pH between 3.2 and 4.18. These soil $\mathrm{pH}$ values are higher than the soil $\mathrm{PZC}_{\mathrm{pH}}$ (3.1) which implies that the soil zeta potential was potentially negative, therefore the EOF direction was from anode to cathode. Test T3 shows $8.3 \%$ less cumulative EOF than that of T2. This trend was expected since EOF cannot be generated during the PR intervals. Also, the PR time was too short to properly generate a negative EOF, i.e., from
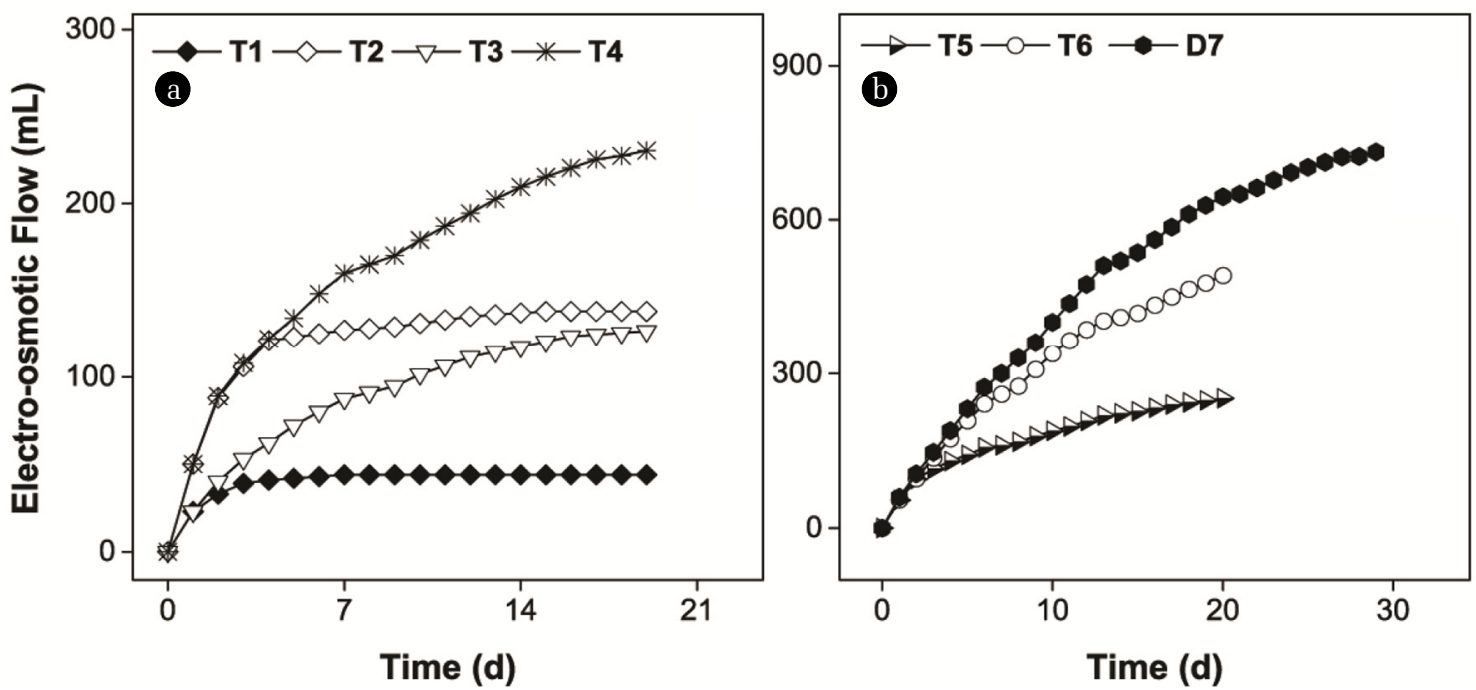

Fig. 4. Cumulative electro-osmotic flow at the end of elecrokinetic tests. 
cathode to anode, hence the poor gap between cumulative EOF values of tests T2 and T3. Several studies reported that although PR technique provides an appropriate $\mathrm{pH}$ for heavy metals extraction, it is often impaired by poor EOF level [25, 41].

Test $\mathrm{T} 4$ shows an average final soil $\mathrm{pH}$ of 3.0, the low $\mathrm{pH}$ implies that zeta potential should be either neutral or slightly positive. Despite the low soil pH, EOF of test T4 was still cumulating in the cathode to reach $230 \mathrm{~mL}$, and no negative EOF was detected. These observations indicate that zeta potential was potentially negative during the EKR process. Yang and Baek [36] reported Similar EOF behavior in EKR process. In test T5, when the Cpc and PR were coupled, Cumulative EOF, as shown in Fig. 4(b), hardly varied in regard to test T4. This confirms the insignificance of negative EOF that may be produced in this limited PR time.

In test T6, polarity reversal time was reduced to $30 \mathrm{~min}$ and its voltage gradient was tripled. The use of PR was not meant to regulate the $\mathrm{pH}$ because $30 \mathrm{~min}$ was too short of a time to create a window of suitable $\mathrm{pH}$ in the cathode. However, the strategy aimed to shake the soil charged particles and possibly minerals that potentially were blocking the incoming water flow. Cumulative EOF of test T6 (492 mL) was enhanced to nearly double that of T5 $(251 \mathrm{~mL})$. The authors hypothesize that this maneuver may have created very small gaps within the soil, which allowed a better flow of the interstitial fluid in soil.

Cumulative EOF, in test D7, was higher $(732 \mathrm{~mL})$ than that of T6. This was probably due to the presence of higher amount of ionic species in soil as a result of: (1) the longer contact of soil with $\mathrm{H}^{+}$ions on account of catholyte $\mathrm{pH}$ control [18]; and/or (2) the amount of heavy metals present in D7 soil. Most of these metals, during EKR process, were in ionic from (divalent ions or complexed ions). The overall ionic species transferred momentum to the surrounding water fluid, and thus enhanced the EOF [6]. Although the current intensity was kept relatively high, the cumulative EOF curve slope drastically decreased. Consequently, an effective rate of EOF did not sustain for more than $13 \mathrm{~d}$ of EKR treatment. As time passed on, more ionic species were introduced into the interstitial fluid due to solubilization and electrokinetic extraction on soil. The increase of ionic species would lower the thickness of the diffused double layer of the pore fluid [42]. This would impair the dielectric properties of the pore fluid and, according to Eq. (3), slow down the cumulative EOF.

\subsection{Heavy Metals Removal}

Masse balance of the EKR experiments, as shown in Table S1, revealed that $\mathrm{Pb}$ and $\mathrm{Cu}$ accumulated at the cathode. This indicates direction and mechanisms of the removal process: from anode to cathode by electromigration and electroosmotic flow.

\subsubsection{Tests without EKR controlled parameters}

The first experiment was carried out with sodium nitrate as purging solution, and resulted in poor $\mathrm{Pb}$ and $\mathrm{Cu}$ removal efficiency of $11 \%$, as shown in Table 3 . Sodium nitrate is a strong electrolyte that can supplement soil medium with ions $\left(\mathrm{Na}^{+}, \mathrm{NO}_{3}{ }^{-}\right)$. It improves the electrical conductivity of the soil, and thus the overall EKR process. However, the capability of $\mathrm{NaNO}_{3}$ as flushing solution is limited as it is unable to neither form complexes nor dissolve heavy metal from soil [43].
The remediation of heavy metals in test $\mathrm{T} 1$ was also restrained by the formation of basic $\mathrm{pH}$ near the cathode compartment. Which favored the formation of complexes such as $\mathrm{Pb}(\mathrm{OH})_{2}$ and $\mathrm{Cu}(\mathrm{OH})_{2}$. These complexes subsequently clogged the soil pores and blocked the decontamination process.

In test T2, citric acid was used as anolyte to be transported by EOF toward the cathode. The removal efficiency was greatly enhanced to reach approximatively $32 \%$ and $30 \%$ of $\mathrm{Cu}$ and $\mathrm{Pb}$. The efficiency of this flushing agent in electroremediation of heavy metals contaminated soil, has been demonstrated and confirmed by many anterior studies $[12,20]$. In addition of providing a low $\mathrm{pH}$ medium, citric acid is a viscous fluid that can decrease the diffuse layer of soil particle, allowing the removal and solubilization of metals ions from the porous media. Also, the ionic species, generated or extracted by citric acid, has potential for improving the electrical conductivity of soil, and thus enhancing the EKR process [44]. Despite the advantages of this washing agent, the decontamination process of $\mathrm{T} 2$ did not show any further enhancement. This could be due to the negative effect of $\mathrm{OH}^{-}$ on heavy metals, and also to the formation of anionic citrate complexes, as presented in Table S2 [45], in basic soil pH near the cathode compartment. The latter complexes could hardly electromigrate toward the anode because of the EOF encountered in the opposite direction.

In all citric acid enhanced experiments (T2-D7), as shown in Fig. 5(a) (d), the removal of $\mathrm{Cu}$ from soil was favored in regard of $\mathrm{Pb}$. This could be explained by the $\mathrm{Cu}$ constant of stability that is always higher than that of $\mathrm{Pb}$ with respect to the same citrate ligand, as shown in Table S2. This implies that citrate ligand has a tendency to form more stable complexes with $\mathrm{Cu}$ than $\mathrm{Pb}$.

\subsubsection{Tests with EKR controlled parameters}

Tests T3-D7 focuses on the optimization of soil EKR conditions for maximum $\mathrm{Pb}$ and $\mathrm{Cu}$ removal. The objective is to work in acid medium to enhance the overall process.

Polarity reversal during soil EKR (PR, EKR) has been tested in Test T3. PR was carried out for a total 9h daily. The frequency was selected to avoid the generation and impact of negative EOF, that could be yielded during PR time, on heavy metals decontamination path which was toward the cathode. When compared to test T2, the removal efficiency of the PR test doubled to reach 62.19 and 58.82\%, respectively of $\mathrm{Cu}$ and $\mathrm{Pb}$. It is assumed that $\mathrm{PR}$ provided a suitable soil conditions for the EKR treatment, as it prevented $\mathrm{pH}$ gradient jump, and no additional buffer electrolyte was required. Moreover, this technique enhanced the remediation process through a better penetration of citric acid into soil which eventually facilitated the extraction, and transportation of $\mathrm{Pb}$ and Cu. Pazos et al. [25], Cai et al. [41] and Lu et al. [34] have tested the polarity reversal technique on heavy metals contaminated soil. They all concluded that PR is efficient against the formation of acid and basic front during the soil EKR process. The results of experiment T3, as presented in Fig. 5(a), and 5(c), lead to the same conclusion. Nonetheless complete removal was not attained. In test $\mathrm{T} 3$, the $\mathrm{pH}$ of soil sections 3 to 5 ranged from 5.1 to 6.8 . According to the $\mathrm{pKa}$ of citric acid, these $\mathrm{pH}$ values probably promoted the formation of neutral complexes, such as $\mathrm{PbH}_{2} \mathrm{Cit}$ and $\mathrm{CuH}_{2}$ Cit. The mobility of these nonionic species by advection, 

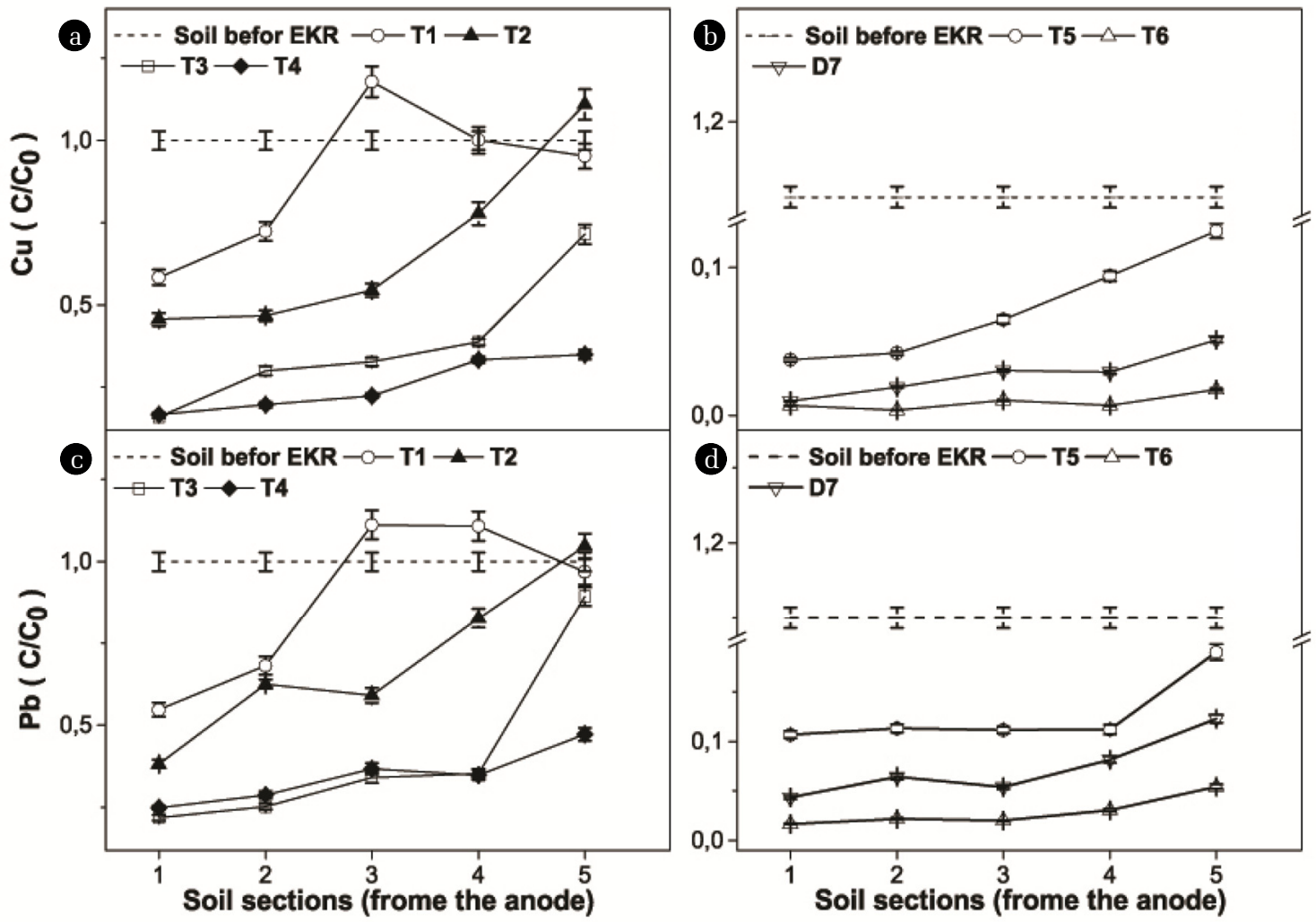

Fig. 5. Normalized concentrations of lead and copper after electrokinetic treatment.

in the interstitial fluid, is very low. Hence the difficulty of their removal by the EKR process [46]. Cumulative EOF of test T3 was low and practically stopped. Since the remediation of precipitates relied only on EOF, the decontamination process ended, thus the rest of heavy metals remained in soil.

The R\% results of Test T4 showed approximatively 10\% improvement of both metals with respect to test T3. It could be due to the acidic soil environment induced by the addition of acetic acid directly into the catholyte. In acid medium, $\mathrm{Pb}$ and $\mathrm{Cu}$ are desorbed from soil surface, by citric acid enhanced EKR, into the interstitial fluid in two possible forms: divalent ions $\left(\mathrm{Cu}^{2+}\right.$ or $\left.\mathrm{Pb}^{2+}\right)$ and/or soluble cationic citrate complexes [47]. In test $\mathrm{T} 4$, soil $\mathrm{pH}$ ranged from 3 to 2 which means that citric acid was in $\mathrm{H}_{2} \mathrm{Cit}^{-}$ligands form, conforming with its $\mathrm{pKa}$ value. The ligands formed cationic citrate complexes, such as $\mathrm{Pb}\left(\mathrm{H}_{2} \mathrm{Cit}\right)^{+}$and $\mathrm{CuH}_{2} \mathrm{Cit}^{+}$. These species electromigrated toward the cathode in the same direction as normal EOF which favored the decontamination process. Furthermore, these positively charged molecules, are very stable water soluble complexes due to their relatively high values of the stability constants, as shown in Table S2. This indicates the high potential of citric acid to enhance the EKR process. Similar results are obtainable by chelating metals with EDTA. Song et al. [48] used EDTA as flushing solution and applied a $\mathrm{Cpc}$ (at $\mathrm{pH}$ 2) in EKR of $\mathrm{Pb}$ and Cd contaminated red soil, the EOF generated toward the anode due to very low soil $\mathrm{pH}$. They confirmed that the main EKR mechanisms for metal- EDTA (EDTA-Me ${ }^{-2}$ ) transport in soil are both EOF and electromigration (toward the anode).
However, the soil remediation, once again, was not complete. The cause for process limitation could be due to a clogging happening in the soil pores by the aggregation of soil colloid particles. More specifically, partial soil particles were transported with EOF, which increased the percentage of aggregation of soil colloid particles [49]. This remolded the flocculated soil fabric into aggregated fabric [50] and subsequently, the soil had little to no void fraction. Correspondingly, the EKR mechanisms were forced to shut down.

The purpose of test T5, T6 and D7 is to overcome the clogging of soil pore particles emphasized in test T4. In test T5, PR and Cpc are used simultaneously on soil EKR. The R\% increased up to $92.73 \%$ and $87.32 \%$ of respectively $\mathrm{Pb}$ and $\mathrm{Cu}$. The combination of Both EKR enhancers highly and effectively reduced the influence of $\mathrm{pH}$ variation on soil caused by water electrolysis. Consequently, avoiding any metal precipitates that could clog the soil pore, thus, favoring the EKR decontamination mechanisms (EOF and electromigraion) on $\mathrm{Pb}$ and $\mathrm{Cu}$ from soil. Moreover, the enhancement observed in test $\mathrm{T} 5$ could also be attributed to a low rate of the aggregate colloid particles, in soil sections near the cathode. The authors of this paper hypothesize that the clogging of soil particles was probably reduced by the application of PR intervals. During which, charged particles in soil could have electromigrated back and forth, for a very small and restricted distance considering that PR time was limited (see Fig. S1), by the repetitive change of medium polarity. These movements would have transferred enough momentum to move the surrounding small aggregate soil particles, thereby creating or unclogging potential paths within 
the pores soil network for heavy metals transportation.

Test T6 resulted in the best removal efficiency with more than $97 \%$ of total decontamination. This could be principally owed to a better flow of the interstitial fluid across the EKR cell. Unlike test T5, experiment T6 produced more cumulative EOF which allowed a better current conductivity. This generation of higher volumes of EOF was favored considering that the normal EKR treatment time was increased by reducing the PR time, as shown in Fig. S1(b). One could argue, with a short PR application, how could the pore particles, near the cathode, be kept free of colloid particles aggregation. The answer could be in the application of 3.0 times the initial voltage gradient, i.e. $3 \mathrm{DCV} / \mathrm{cm}$, during the 30 min of polarity reversal. The stress of these multiple electric shocks, per day in soil, may have created small cracks in the clogged area of soil. During this stress, ionic species strongly electromigrated, in the opposite direction, by the high DC voltage. The transport of these ionic species may have induced the movement of nano particles, thus clearing small paths for the pore water fluid. Consequently, the interstitial fluid spread through the small gaps, created by the electric shocks, and enhanced the overall process through a better function of the EKR main mechanisms. Since the heat of soil increases the sorption of heavy metals into soil, the PR was also limited to $30 \mathrm{~min}$ to avoid the joule effect [51].

As expected, the removal efficiency of test D7 was close to that of test T6. This behavior can be explained by the same controlled parameter in both experiments, and can be confirmed by the similarity of R\% trend in all soil sections, as shown in Fig. 5(b), and 5(d). In test D7, Soil 2 contained 10,000 mg/kg of each contaminant $(\mathrm{Pb}$ and $\mathrm{Cu})$. The treatment time was extended to $29 \mathrm{~d}$, as the heavy metals removal was not finished. EOF still cumulated and the current intensity leveled off at high values due to the presence of higher amount of ions, in the porous media, and to the low soil $\mathrm{pH}$. These conditions favored, proportionately, an efficient soil decontamination of $97.22 \%$ and $92.67 \%$ of respectively $\mathrm{Cu}$ and $\mathrm{Pb}$.

Additional data, figures and captions of this work are provided as supplementary materials: $\mathrm{Pb}$ and $\mathrm{Cu}$ content in soil before and after EKR treatment is presented, respectively, in Table S3 and Table S4. Pictures of the EKR main compartment in test T6 at different time laps are presented in Fig. S3, Fig. S4, Fig. S5 and Fig. S6. Also, pictures of the soil chamber in Test D7 at different time laps is provided in Fig. S7, Fig. S8 and Fig. S9.

\subsection{Power Consumption}

The results of power consumption per unit weight of soil $\left(\mathrm{kWh} . \mathrm{t}^{-1}\right)$ were estimated and reported in Table 3. The EKR pH control techniques required more energy consumption than that of the conventional EKR. The catholyte controlled $\mathrm{pH}$ in test $\mathrm{T} 4$ increased the Pc due to the addition of $\mathrm{H}^{+}$and $\mathrm{CH}_{3} \mathrm{COO}^{-}$in the system which favored a better electric conductivity. The application of both PR and Cpc resulted in higher Pc, it is probably due to a better transport of the pore water fluid by EOF, thus favoring a better current intensity. The energy consumption increased relatively with the soil moisture content and efficiency removal. Soil moisture enhanced the passage of electrical current through the soil. Therefore, enabling a better performance of the EKR mechanisms enhanced the R\%. The soil of test D7 required 10 more days of EKR process than that of test $\mathrm{T} 6$ because of the high $\mathrm{Cu}$ and $\mathrm{Pb}$ content. This time extension along with metals content resulted in a highest power consumption with 1,556 kWh.t $\mathrm{t}^{-1}$. In short, the current consumption of this study depended on soil moisture, metal content and EKR treatment time. Overall, the power consumption is relatively low when compared with other remediation techniques [6]. The results of the enhanced electrokinetic soil remediation, presented in this paper, suggest that this process could be an effective alternative for the decontamination of soil contaminated with heavy metals such as $\mathrm{Pb}$ and $\mathrm{Cu}$. Nevertheless, the lab scale experiments of this work should be performed on pilot scale in order to extrapolate results and useful information for potential field scale application. The energy consumption should be inversely related to the experimental scale; i.e. bigger scale process requires less electric power [23].

\section{Conclusions}

This paper shows promising results for the application of electrokinetic soil remediation on aged heavy metal contaminated soil. The use of citric acid alone with EKR was not sufficient to remediate $\mathrm{Pb}$ and $\mathrm{Cu}$ from soil. The addition of periodic polarity reversal or catholyte $\mathrm{pH}$ control techniques separately increased the removal efficiency but did not achieve complete soil depollution. On one hand, these techniques could potentially yield better results if the EKR duration time was extended but will surely result in more power consumption. On the other hand, with the same $19 \mathrm{~d}$ of experiment, better results were obtained when the two enhancing techniques were combined together. Furthermore, this combination is hypothesized to have overcome the problem of soil clogging caused by the aggregation of colloid particles and heavy metals precipitates. Finally, coupling EKR with a combination of periodic Polarity reversal electric shock and Catholyte $\mathrm{pH}$ control yielded the best removal efficiency with $99.11 \%$ of $\mathrm{Cu}$ and $97.13 \%$ of $\mathrm{Pb}$. These results are mainly owed to (i) the Cpc that provided an ideal soil $\mathrm{pH}$ for $\mathrm{Pb}$ and $\mathrm{Cu}$ removal. (ii) The short time of $\mathrm{PR}$ which increased the cumulative EOF, and therefore enhancing the R\%. (iii) The stress caused by the repetitive PR electric shocks on charged particles within soil, which possibly have created small gaps within the clogged soil pores, and assured a path of transport for heavy metals. This method is proposed as a new approach for large scale applications.

\section{Acknowledgment}

This manuscript is supported by The university of science and technology Houari Boumediene (USTHB) in Algeria.

\section{Author Contributions}

All authors contributed to the study conception and design. O.M.B (Ph.D.) performed all experiments and analysis along with data 
collection, discussion of the results, and wrote the manuscript. O.M. (Ph.D. student/engineer in physical and chemical analysis) worked on the chemical analysis and data plotting. D.E.A. (professor) revised and edited the manuscript.

\section{References}

1. Ashraf MA, Maah MJ, Yusoff I. Soil Contamination, Risk Assessment and Remediation, Environmental Risk Assessment of Soil Contamination: Maria C. Hernandez-Soriano, IntechOpen; 2014.

2. Tahar K, Keltoum B. Effects of heavy metals pollution in soil and plant in the industrial area, West Algeria. J. Korean Chem. Soc. 2011;55(6):1018-1023.

3. Yeung AT. Milestone developments, myths, and future directions of electrokinetic remediation. Sep. Purif. Technol. 2011;79(2):124-132.

4. Khalid S, Shahid M, Niazi NK, Murtaza B, Bibi I, Dumat C. A comparison of technologies for remediation of heavy metal contaminated soils. J. Geochem. Explor. 2017;182:247-268.

5. Cameselle C, Gouveia S. Electrokinetic remediation for the removal of organic contaminants in soils. Curr. Opin. Electrochem. 2018;11:41-47.

6. Reddy KR, Cameselle C. Electrochemical remediation technologies for polluted soils, sediments and groundwater: John Wiley \& Sons; 2009.

7. Zhou H, Xu J, Lv S, Liu Z, Liu W. Removal of cadmium in contaminated kaolin by new-style electrokinetic remediation using array electrodes coupled with permeable reactive barrier. Sep. Purif. Technol. 2020;239:116544.

8. Li J, Ding Y, Wang K, et al. Comparison of humic and fulvic acid on remediation of arsenic contaminated soil by electrokinetic technology. Chemosphere 2020;241:125038.

9. Merdoud O, Cameselle C, Boulakradeche MO, Akretche DE. Removal of heavy metals from contaminated soil by electrodialytic remediation enhanced with organic acids. Environ. Sci.: Processes Impacts 2016;18(11):1440-8.

10. Yuan L, Xu X, Li H, Wang N, Guo N, Yu H. Development of novel assisting agents for the electrokinetic remediation of heavy metal-contaminated kaolin. Electrochim. Acta 2016;218:140-148.

11. Pazos M, Alcántara M, Cameselle C, Sanromán M. Evaluation of electrokinetic technique for industrial waste decontamination. Sep. Sci. Technol. 2009;44(10):2304-2321.

12. Cameselle C, Pena A. Enhanced electromigration and electro-osmosis for the remediation of an agricultural soil contaminated with multiple heavy metals. Process Saf. Environ. Prot. 2016;104:209-217.

13. Asadollahfardi G, Rezaee M. Electrokinetic remediation of diesel-contaminated silty sand under continuous and periodic voltage application. Environ. Eng. Res. 2019;24(3):456-462.

14. Tahervand S, Jalali M. Sorption, desorption, and speciation of $\mathrm{Cd}, \mathrm{Ni}$, and Fe by four calcareous soils as affected by $\mathrm{pH}$. Environ. Monit. Assess. 2016;188(6):322.

15. Ouhadi V, Yong R, Shariatmadari N, Saeidijam S, Goodarzi A, Safari-Zanjani M. Impact of carbonate on the efficiency of heavy metal removal from kaolinite soil by the electrokinetic soil remediation method. J. Hazard. Mater. 2010;173(1-3):87-94.

16. Zhu S, Han D, Zhou M, Liu Y. Ammonia enhanced electrokinetics coupled with bamboo charcoal adsorption for remediation of fluorine-contaminated kaolin clay. Electrochim. Acta 2016;198:241-248.

17. Villen-Guzman M, Garcia-Rubio A, Paz-Garcia JM, VeredaAlonso C, Gomez-Lahoz C, Rodriguez-Maroto JM. Aging effects on the mobility of $\mathrm{Pb}$ in soil: Influence on the energy requirements in electroremediation. Chemosphere 2018;213:351-357.

18. Ryu B-G, Park G-Y, Yang J-W, Baek K. Electrolyte conditioning for electrokinetic remediation of $\mathrm{As}, \mathrm{Cu}$, and $\mathrm{Pb}$-contaminated soil. Sep. Purif. Technol. 2011;79(2):170-176.

19. López-Vizcaíno R, Yustres A, Sáez C, Cañizares P, Rodrigo M, Navarro V. Effect of polarity reversal on the enhanced electrokinetic remediation of 2, 4-D-polluted soils: A numerical study. Electrochim. Acta 2017;258:414-422.

20. Song Y, Benamar A, Mezazigh S, Wang H. Citric acid-enhanced electroremediation of toxic metal-contaminated dredged sediments: effect of open/closed orifice condition, electric potential and surfactant. Pedosphere 2018;28(1):35-43.

21. Bahemmat M, Farahbakhsh M, Kianirad M. Humic substances-enhanced electroremediation of heavy metals contaminated soil. J. Hazard. Mater. 2016;312:307-318.

22. Fu R, Wen D, Xia X, Zhang W, Gu Y. Electrokinetic remediation of chromium (Cr)-contaminated soil with citric acid (CA) and polyaspartic acid (PASP) as electrolytes. Chem. Eng. J. 2017;316:601-608.

23. Villen-Guzman M, Paz-Garcia JM, Rodriguez-Maroto JM, Gomez-Lahoz C, Garcia-Herruzo F. Acid enhanced electrokinetic remediation of a contaminated soil using constant current density: strong vs. weak acid. Sep. Sci. Technol. 2014;49(10): 1461-1468.

24. Cang L, Fan G-P, Zhou D-M, Wang Q-Y. Enhanced-electrokinetic remediation of copper-pyrene co-contaminated soil with different oxidants and $\mathrm{pH}$ control. Chemosphere 2013;90(8): 2326-2331.

25. Pazos M, Sanroman M, Cameselle C. Improvement in electrokinetic remediation of heavy metal spiked kaolin with the polarity exchange technique. Chemosphere 2006;62(5):817-822.

26. Sekkoum K, Talhi M-F, Cheriti A, et al. Advancing Desalination: Water in Algerian Sahara, Environmental and Health impact: Robert Y. Ning, IntechOpen; 2012.

27. Kelebemang M, Dinake P, Sehube N, Daniel B, Totolo O, Laetsang M. Speciation and mobility of lead in shooting range soils, Chem. Speciation Bioavailability 2017;29(1):143-152.

28. Boulakradeche MO, Akretche DE, Cameselle C, Hamidi N. Enhanced electrokinetic remediation of hydrophobic organics contaminated soils by the combination of non-ionic and ionic surfactants. Electrochim. Acta 2015;174:1057-1066.

29. US EPA Method 9045D. Soil and Waste pH. Soil and Waste pH: U.S. Environ. Prot. Agency; 2004. p. 1-5.

30. DIN ISO 10694. Soil quality-Determination of organic and total carbon after dry combustion (elementary analysis). Geneva, Switzerland: International Organization for Standardization (ISO); 1995.

31. Edgell K. USEPA method study 37 SW-846 method 3050 acid 
digestion of sediments, sludges, and soils: U.S. Environ. Prot. Agency; 1989.

32. Pansu M, Gautheyrou J. Handbook of soil analysis: mineralogical, organic and inorganic methods: Springer Science \& Business Media; 2007.

33. US EPA, Test methods for evaluating solid wastes. Physical/ chemical methods. SW-846 manual. EPA Method 3010A: acid digestion of aqueous samples and extracts for total metals for analysis byflame atomic absorption spectroscopy (FLAA) or in-ductively coupled plasma spectroscopy (ICP): U.S. Environ. Prot. Agency; 1992.

34. Lu P, Feng Q, Meng Q, Yuan T. Electrokinetic remediation of chromium-and cadmium-contaminated soil from abandoned industrial site. Sep. Purif. Technol. 2012;98:216-20.

35. Schneller T, Waser R, Kosec M, Payne D. Chemical solution deposition of functional oxide thin films: Springer; 2013.

36. Yang J-S, Kwon MJ, Choi J, Baek K, O'Loughlin EJ. The transport behavior of $\mathrm{As}, \mathrm{Cu}, \mathrm{Pb}$, and $\mathrm{Zn}$ during electrokinetic remediation of a contaminated soil using electrolyte conditioning. Chemosphere 2014;117:79-86.

37. Yeung AT, Corapcioglu M. Electrokinetic flow processes in porous media and their applications. Adv. Porous Media 1994;2(4):309-95.

38. Al-Hamdan AZ, Reddy KR. Transient behavior of heavy metals in soils during electrokinetic remediation. Chemosphere 2008;71(5):860-871.

39. Kim S-O, Kim W-S, Kim K-W. Evaluation of electrokinetic remediation of arsenic-contaminated soils. Environ. Geochem. Health. 2005;27(5-6):443-453

40. Rozas F, Castellote M. Electrokinetic remediation of dredged sediments polluted with heavy metals with different enhancing electrolytes. Electrochim. Acta 2012;86:102-109.

41. Cai Z-p, Van Doren J, Fang Z-q, Li W-s. Improvement in electrokinetic remediation of $\mathrm{Pb}$-contaminated soil near lead acid battery factory. Trans. Nonferrous Met. Soc. China 2015;25(9): 3088-3095.
42. Alshawabkeh AN, Sheahan TC, Wu X. Coupling of electrochemical and mechanical processes in soils under DC fields. Mech. Mater. 2004;36(5-6):453-465.

43. Ng YS, Gupta BS, Hashim MA. Performance evaluation of two-stage electrokinetic washing as soil remediation method for lead removal using different wash solutions. Electrochim. Acta 2014;147:9-18.

44. Li G, Guo S, Li S, Zhang L, Wang S. Comparison of approaching and fixed anodes for avoiding the 'focusing'effect during electrokinetic remediation of chromium-contaminated soil. Chem. Eng. Technol. 2012;203:231-238.

45. Torres R, Lapidus GT. Closed circuit recovery of copper, lead and iron from electronic waste with citrate solutions. Waste Manage. 2017;60:561-568.

46. Yeung AT, Hsu C-n, Menon RM. Physicochemical soil-contaminant interactions during electrokinetic extraction. J. Hazard. Mater. 1997;55(1-3):221-237.

47. Bolt GH, De Boodt M, Hayes MH, McBride M, De Strooper E. Interactions at the Soil Colloid: Soil Solution Interface: Springer Science \& Business Media; 2013.

48. Song Y, Cang L, Xu H, Wu S, Zhou D. Migration and decomplexation of metal-chelate complexes causing metal accumulation phenomenon after chelate-enhanced electrokinetic remediation. J. Hazard. Mater. 2019;377:106-112.

49. Cheng F, Guo S, Li G, Wang S, Li F, Wu B. The loss of mobile ions and the aggregation of soil colloid: Results of the electrokinetic effect and the cause of process termination. Electrochim. Acta 2017;258:1016-1024.

50. Wu H, Hu L. Microfabric change of electro-osmotic stabilized bentonite. Appl. Clay Sci. 2014;101:503-509.

51. Hahladakis JN, Calmano W, Gidarakos E. Use and comparison of the non-ionic surfactants Poloxamer 407 and Nonidet P40 with HP- $\beta$-CD cyclodextrin, for the enhanced electroremediation of real contaminated sediments from PAHs. Sep. Purif. Technol. 2013;113:104-113. 